\title{
A Multi-Criteria Decision Process for EV Charging Stations' Deployment: Findings from Greece
}

\author{
Leonidas Anthopoulos $1, *\left(\mathbb{D}\right.$ and Polytimi Kolovou ${ }^{2}$ \\ 1 Department of Business Administration, Geopolis Campus, University of Thessaly, Larissa Ringroad, \\ 41500 Larissa, Greece \\ 2 School of Science and Technology, MSc in Engineering Management, Hellenic Open University, \\ 18 Aristotelous Side Road, 26335 Patras, Greece; std131666@ac.eap.gr \\ * Correspondence: lanthopo@uth.gr; Tel.: +30-693-210-0198
}

Citation: Anthopoulos, L.; Kolovou, P. A Multi-Criteria Decision Process for EV Charging Stations' Deployment: Findings from Greece. Energies 2021, 14, 5441. https:// doi.org/10.3390/en14175441

Academic Editors: Umberto Berardi and Teresa Galvão Dias

Received: 2 June 2021

Accepted: 22 August 2021

Published: 1 September 2021

Publisher's Note: MDPI stays neutral with regard to jurisdictional claims in published maps and institutional affiliations.

Copyright: (c) 2021 by the authors. Licensee MDPI, Basel, Switzerland. This article is an open access article distributed under the terms and conditions of the Creative Commons Attribution (CC BY) license (https:// creativecommons.org/licenses/by/ $4.0 /)$.

\begin{abstract}
Electro-mobility (EV) is an emerging transportation method, whose charging infrastructure development concerns a key-factor for its growth. EV charging infrastructure has not grown yet in Greece, regardless of the ambitious national targets that have been grounded for 2030 towards a climate-neutral mobility. This study introduces a multi-criteria decision-making (MCDM) framework for EV charging infrastructure deployment and operation, which respects both the economic and the technical aspects for public charging stations. The analytic hierarchy process (AHP) was followed for the MCDM framework's definition, which used criteria that were in the corresponding literature and performed with interviews by experts from the EV growing market in Greece. The results show that the installation and operation of public EV charging stations, located in private spaces to ensure their protection against vandalism, within the urban areas is the preferred deployment approach. Moreover, this article tests a market model for the EV charging infrastructure ownership and operation. Findings show that the incentive for investment in EV charging infrastructure market in Greece, is driven by the direct investments of limited vendors, while it is not economically oriented, but it focuses on sustainability and environmental protection.
\end{abstract}

Keywords: electric vehicle; EV; charging stations; MCDM; AHP; business model; smart city; smart mobility

\section{Introduction}

Infrastructure for vehicles' alternative fueling concerns a key factor for the fleet upgrades that will be able to reduce greenhouse gas emissions generated by transportation, especially in cities. Today, the European Green Deal [1,2] introduces changes in the mobility sector with the introduction of policies that encourage alternative fueling $[3,4]$ and electric vehicles (EV) [3]. Electro-mobility has become a popular alternative transportation method both in Europe and internationally. According to the International Energy Agency [5], the global EV fleet exceeded 5.1 million in 2018, with China "leading the race" as the largest EV market, followed by Europe. Moreover, EV sales are expected to reach 23 million by 2030 internationally.

However, a crucial issue for the adoption of electro-mobility is the deployment of accessible charging infrastructure. The lack of such an infrastructure, together with the comparable high price and the limited range of EV, are key barriers for EV penetration [6,7]. Moreover, the economic viability of charging infrastructure's investments has been studied and questioned [8-10], especially for the fast charging stations. EV refueling lacks significantly compared to the internal combustion engine vehicles due to the missing refueling equipment, long charging duration, number of alternative charging methods, types of access, etc. [8,9]. In addition, the business models for electro-mobility are based on complex relationships between customers and operators [11]. 
Especially in Greece, charging infrastructure deployment and EV fleet size are both limited. In 2019 only, 40 normal power recharging points $(\leq 22 \mathrm{~kW})$ and 18 high power recharging points $(\geq 22 \mathrm{~kW})$ existed in the country, while the amount of EV (including plug-in hybrid electric vehicle (PHEV) vehicles) rose from 856 in 2019 to 2031 in 2020 [3,4]. Meanwhile, the official national objectives for EV growth are quite optimistic. According to the Greek Plan for Energy and Climate [12], the estimated size for EV and PHEV together, are expected to reach the numbers of 20.257 in 2025 and 66.371 in 2030, respectively (baseline scenario), and 24.036 and 82.422 in the same years, according to the scenario for higher economic growth.

In this context, good opportunities for investing in the EV charging infrastructure market are generated, while at the same time several challenges arise due to the complex EV market's structure. This paper addresses the opportunities and challenges in the EV market by answering the following research questions (RQs):

RQ1: What are the technical characteristics of EV charging stations for publicly accessible and what are the business models for their deployment?

RQ2: What is the most suitable business model for EV charging network's deployment and operation in Greece?

Both questions are important to be answered due to the increasing EV market share and the political encouragement for alternative fuel use. In this regard, RQ1 will present the alternative options for companies that are interested in entering the EV charging network's market. On the other hand, RQ2 presents findings from a typical European country regarding the decision-making process that can be followed by such companies. In this regard, this paper uses a decision-making framework to determine the optimal approach for developing and operating an EV charging stations' network from the investors' / stakeholders' point of view in Greece. The framework is based on both quantitative and qualitative criteria (economic, technical, social, environmental, and political), while the analytic hierarchy process (AHP) is followed by a sample of representatives from the corresponding energy providing market.

Literature review findings contributed to the definition of the criteria that affect the corresponding decision-making, while the relative importance of identified criteria was rated by the participants in the AHP study. The overall AHP methodology was performed with the support of the Expert Choice ${ }^{\circledR}$ software.

The rest of this paper is organized as follows: Section 2 concerns a background analysis of this article and contains the literature review findings. Then, Section 3 presents the research methodology, while Section 4 provides answers to the grounded RQs together with some limitations and future thoughts.

\section{Literature Review}

To identify the criteria that affect the corresponding decision making, a literature review was performed in the scientific libraries Google Scholar and Scopus, in the period that this study took place (December 2019 and July 2020). A combination of the keywords ("EV", "charging infrastructure", and "business model") returned approximately 2300 and 102 results, respectively. Irrelevant works to this article's scope were excluded (i.e., electricity market and power grid, wireless charging, or battery swapping method, etc.) and an amount of 41 articles contributed to this study. Moreover, some technical reports and corresponding legal framework were used to support the definition of the criteria. The outcomes of this review are summarized in the following sub-sections and provide answer RQ1.

\subsection{Charging Infrastructure for $E V$}

Charging infrastructure is a component of the overall e-mobility system and it is particularly important as it specifies the EV connection to the power grid and its charging. This component has several characteristics that affect the value proposition of the charging infrastructure and the design of the cost model for its implementation and operation [8]. 
These characteristics include the type of power supply; the device power level; the control and communication systems; the connector types; the type of access; and the billing policy. Conductive (wired) charging that is based on a cable connection between the EV and the power network, is the basis of this study.

In accordance with European Directive 2014/94/EU and the European Green Deal [1] on the deployment of alternative fuels' infrastructure, public charging points allow nondiscriminatory access to the EV users, enabling various means for user identification and payment. The charging points-according to the power level—are classified to normal power charging points with a power level up to $22 \mathrm{~kW}$, and high-power charging points with a power of more than $22 \mathrm{~kW}$.

The general requirements for the conductive charging system in Europe are defined in the IEC 61851-1 standard [13] while in the United States the SAEJ1772 standard has been adopted [14]. The international IEC 61851-1 standard "EV conductive charging systemPart 1: General requirements" [13] specifies how the EV of any type is connected to the power supply network and the requirements of the charging equipment. Moreover, this standard defines four charging modes (methods) according to communication, safety, and power capacity characteristics of the EV supply equipment. These four charging modes and their characteristics are summarized in Table 1.

Table 1. Characteristics of charging modes according to IEC 61851-1:2017.

\begin{tabular}{|c|c|c|c|c|}
\hline Feature & Mode 1 & Mode 2 & Mode 3 & Mode 4 \\
\hline Communication and safety control device & No & Yes (in-cable control box) & Yes & Yes \\
\hline Current type & $\mathrm{AC}$ & $\mathrm{AC}$ & $\mathrm{AC}$ & DC \\
\hline Maximum current (A) & $16 \mathrm{~A}$ & $32 \mathrm{~A}$ & $63 \mathrm{~A}$ & - \\
\hline Output power $(\mathrm{kW})$ & $3.7-11 \mathrm{~kW}$ & $3.7-22 \mathrm{~kW}$ & $\begin{array}{c}\text { maximum } 43 \mathrm{~kW} \\
\text { (depends on connector) }\end{array}$ & depends on station \\
\hline
\end{tabular}

On the other hand, Greek legislation which specifies the technical requirements for public charging points [15] defines the charging devices equipped with the Mode $3 \mathrm{AC}$ or Mode 4 DC charging method. The main features of these two methods according to IEC 61851-1:2017 [13] are summarized below, according to the international standard reviews [14,16-18] for charging stations.

- $\quad$ Mode 3: Slow or fast charging in AC current, 1-phase or 3-phase voltage, and maximum current of $63 \mathrm{~A}$. Usually Mode 3 charging devices deliver output power levels of $11 \mathrm{~kW}, 22 \mathrm{~kW}$ or $43 \mathrm{~kW}$. The charging device allows communication with the EV and the protection function ensures the proper connection of the vehicle and the presence of grounding system. The conversion of AC to DC takes place in the vehicle (on-board). The charging time depends on the power levels. In the case of a three-phase supply and a power of $22 \mathrm{~kW}$, the charging time shall be between 1 and $3 \mathrm{~h}$.

- Mode 4: Fast or rapid charging in DC current, delivering output power from 50$175 \mathrm{~kW}$. The charging cable is permanently attached to the charging station. The charger includes the control and communication system ensuring the proper connection, the grounding connection, and monitoring the EV charging. AC to DC conversion occurs at the charging station. In the case of $50 \mathrm{~kW}$ power, EV fully charging lasts approximately 20 to $30 \mathrm{~min}$.

To ensure the interoperability of the charging system, many international standards have been adopted to determine the requirements for the connectors and socket-outlets of the charging station. The main types of connectors in Europe are:

- Type 1: Complies with the IEC 62196-2 standard and reflects the specifications of SAEJ1722 standard [14]. According to IEC 62196-2, its use is acceptable for single phase AC $32 \mathrm{~A} / 230 \mathrm{~V}$ connections, with a maximum power of $7.4 \mathrm{~kW}$.

- Type 2: Connector compliance with the requirements of IEC 62196-2, supports 1-phase and 3-phase charging connections and offers power up to $22 \mathrm{~kW} \mathrm{(32} \mathrm{A/400} \mathrm{V/3-}$ phase), when the connecting cable is detachable or $43 \mathrm{~kW}(63 \mathrm{~A} / 400 \mathrm{~V} / 3$-phase) when 
the cable is permanently attached to the charging device [17]. It is broadly used in Europe, and also known as "Mennekes".

- Type 2 Combo: It is an enhanced version of the Type 2 connector, combining AC and DC charging into a single connector. It complies with the IEC 62196-3 requirements. Its standardization is quite recent, and is promoted by the European automotive industry as an alternative to the DC charging [14].

- CHAdeMO: Internationally widespread connector of the Japanese company TEPCO for DC charging with a maximum output power of $50 \mathrm{~kW}$, having high security features and equipped with the largest number of pins (10 pins) compared to the other connectors. It is a popular solution for fast charging due to the large penetration of first-generation Japanese EV into the European market [17].

The interoperability of the connecting system and the alternative EVs is an important factor for the utilization of charging stations. The need for high interoperability levels is pointed out by the research of [18] on charging systems of EV in Spain. In terms of charging connector, $33 \%$ of EVs are compatible with a DC CHAdeMO connector, $25 \%$ with an AC Type 2 connector (Mennekes), and only 16.7\% with a Type 2 Combo. The Type 1 AC connector, which as mentioned above supports only one-phase charging with a maximum power of $7.4 \mathrm{~kW}$ (slow charging), is used by most EVs at a level of $58.3 \%$.

An extensive charging infrastructure network has a positive effect on EV users in terms of shifting car ownership from traditional fossil fuels to EV. The development of a public infrastructure network includes normal power charging points (normal or slow charging) of up to $22 \mathrm{~kW}$ and high-power charging points (fast charging) of more than $22 \mathrm{~kW}$. Selecting the appropriate technology in combination with the appropriate stations location is crucial to the viability of an investment in the charging infrastructure, since the operator of the charging infrastructure must recoup the investment costs, while offering a competitive service. The two AC and DC charging technologies, usually normal and high power respectively, each present both limitations and advantages. Some key differences between these two technical solutions are highlighted, which serve to identify factors for the AHP research model.

Fast charging network: Fast charging (high power) stations along driving corridors are considered vital for a range of EVs $[10,19]$ and contribute to an increasing EV diffusion as they enable longer distance trips [20-22]. The research of Levinson and West [23] moves the correlation between fast charging infrastructure and EV penetration forward. The authors conclude that the development of fast charging infrastructure is more effective than normal power charging stations in increasing EV sales.

Economic data of charging stations: Charging infrastructure costs can be classified in three categories: Investment costs; fixed operating costs; and variable operating costs [24]. Investment costs concern equipment ownership and installation, grid connection, and licensing expenditures. According to the Progress Report of the German National Platform for Electric Mobility [25], investment costs differ significantly between a $2 \times 22 \mathrm{~kW} \mathrm{AC}$ charging station and a $50 \mathrm{~kW}$ DC one. Although data are quite old, they were used during the determination and execution of this study since they represented the terms of reference for the development of Greek national framework for EV. The numbers that appear in Table 2 are not precise cost figures but provide a clear picture of the economic parameters that serve this study to highlight the cost differences between the two technological options. 
Table 2. Investment and operating costs of normal and high-power charging stations.

\begin{tabular}{ccc}
\hline Economic Data & $\begin{array}{c}\mathbf{2} \times \mathbf{2 2} \mathbf{~ k W ~ A C} \\
\text { Charging Station }\end{array}$ & $\begin{array}{c}\mathbf{1} \times \mathbf{5 0} \mathbf{~ k W ~ D C} \\
\text { Charging Station }\end{array}$ \\
\hline Cost of equipment incl. smart meter $(€)$ & 5000 & 25,000 \\
Grid connection costs $(€)$ & 2000 & 5000 \\
Authorization and planning costs $(€)$ & 1000 & 1500 \\
Installation and building costs $(€)$ & 2000 & 3500 \\
Total investment cost $(€)$ & 10,000 & 35,000 \\
Operating cost $(€ / \mathrm{yr})$ & 1500 & 3000 \\
\hline
\end{tabular}

Technical parameters and planning: The selection of the DC charging station location requires rigorous planning, taking into account the architecture of the power grid, and in particular the capacity and the distance from low-voltage transformers [26]. On the other hand, the normal power AC charging stations concern a more flexible option regarding the power grid limitations. However, the optimal location for normal power charging stations is also extremely important due to the parking reservation requirements, especially in urban areas. The charging space reserved in expense of parking spaces of conventional vehicles is one of the issues that must be considered in the allocation of public charging points [19].

\subsection{Charging Infrastructure Market Models}

The EV market involves several stakeholders (e.g., electricity provider, power grid operator, etc.) in comparison to the traditional automotive business model. Moreover, the dispersed architecture of the electricity grid enables refueling in multiple places [11]. The new business models and participants have created the need for organization of the charging infrastructure market to determine the roles and who is responsible for the implementation and operation of the infrastructure.

The Eurelectic report [27] on the organization of the public charging infrastructure market proposed two market models for the European Member States:

- $\quad$ The independent e-mobility market model, where the development and operation of charging infrastructure is carried out by "any market participant" in the context of competitive market. - The integrated infrastructure market model or DSO model, where the charging infrastructure is developed, operated, and owned by the Distribution System Operator (DSO) allowing third parties to provide e-mobility services.

The report contains implementation cases of the above models in European countries such as Germany and the Netherlands-for the independent e-mobility market modeland Ireland and Luxembourg - for the DSO model. The main advantage of the DSO model is that the centralized planning of the system operator allows an organized development of the infrastructure network, while the independent model enables a more flexible deployment [28]. However, international practices of charging infrastructure development and ownership are not limited to the above two models but they include models of public and private sectors as well as mixed models, such as local government funding or public-private partnerships [29]. A typical example of the entirely private model is the case of Tesla and Nissan automotive companies, which developed their own charging infrastructure to lead the EV market. In China, both public and private entities have an active role in charging infrastructure implementation: Fast charging network along driving corridors is developed and owned by state entities, local government construction funding programs, as well as partnerships with the private sector [30]. At the municipality/local government level, various models have been adopted for the development of public charging infrastructure, where the involvement of the municipality varies: From a regulatory role to participation in the investment. In the Netherlands, in addition to central government incentives and funding, major cities such as Amsterdam, Utrecht, and Hague have a prominent role in promoting e-mobility, where public tenders are held for the installation and operation of charging infrastructure [30]. 
In February 2019, the Greek Regulatory Authority for Energy (RAE) published an opinion with respect to the e-mobility market organization, in which the independent e-mobility market model was proposed. In line with RAE's opinion, Law 4710/2020 on the promotion of e-mobility was granted, which determines the regulatory framework for the development of charging infrastructure and the roles of participants in the e-mobility market. The Greek legal framework provides the following:

- The implementation of independent e-mobility market model for development of the charging points (installation and operation by a private entity);

- The Hellenic Electricity Distribution Network Operator (HEDNO) is not allowed to own, develop, manage, and operate public charging points;

- The municipalities may hold open tenders for the concession of the development and operation of public charging points.

To conduct the tenders, the municipalities are expected to develop EV charging plans that specify the location and the amount of charging points in 2021. Significant elements of the tenders such as the award criteria, the obligations of the contractors, and the duration of the concessions have not yet been defined in the existing Greek legal framework.

\section{Research Methodology}

The analytic hierarchy process (AHP) is applied to determine the optimal alternative business model for developing and operating EV charging stations and to provide answer RQ2. The proposed model of this paper respects both economic and technical aspects of the charging devices, while it considers the electromobility market model, as defined in the Greek legal framework.

The AHP is a multi-criteria decision making (MCDM) method [31] and is broadly used in sectors of academia, industry, energy, politics, education, construction, and general government [32]. Furthermore, the functionality of AHP in solving marketing decision-making problems is particularly important, in fields such as portfolio management decisions, new product development practices, and business strategy assessment [31]. Finally, AHP kept on evolving to new directions, such as the application of fuzzy based information and modelling [33], or with symmetric projection group approach [34], etc. The AHP was selected among other multi-criteria methods such as TOPSIS, PROMETHEE II, VIKOR, COPRAS, Best-Worst, and COMET methods due to its clarity, simplicity, and efficiency [35-37], as well as compared to the analytic network process (ANP) [38].

\subsection{Theory of the AHP Method}

The approach of the AHP helps analyze a complex problem in a hierarchical structure model that contains the goal, the factors, and the alternatives. The primary objective of AHP is to evaluate the alternatives, through pairwise comparisons of the factors of the model. Moreover, the method allows the use of both qualitative and quantitative criteria. The implementation of AHP is based on three basic components [31,39]:

Complexity analysis: Decomposing the problem by identifying the goal, criteria, and alternatives, which are represented in levels in the hierarchy tree;

Calculation/estimation methodology: Determining the priorities of the elements of the hierarchy tree. For each hierarchy level, pairwise comparisons of all decision elements are performed with respect to the element in the higher level. The pairwise comparisons allow the quantification of the element importance, expressed in terms of a number, called weight. The research participants/decision makers evaluate the importance of each element over the other using an absolute-number scale known as Saaty's [40] fundamental scale of absolute numbers, shown in Table 3. From the pairwise comparisons of $n$ elements using the above scale, sets of $n$-dimension matrices are developed for each hierarchy level. 
Table 3. Fundamental scale of absolute numbers.

\begin{tabular}{|c|c|c|}
\hline Intensity of Importance & Definition & Explanation \\
\hline 1 & Equal importance & $\begin{array}{l}\text { Two activities contribute } \\
\text { equally to the objective }\end{array}$ \\
\hline 3 & $\begin{array}{c}\text { Weak importance of one over } \\
\text { another }\end{array}$ & $\begin{array}{c}\text { Experience and judgment } \\
\text { slightly favor one activity over } \\
\text { another }\end{array}$ \\
\hline 5 & Essential or strong importance & $\begin{array}{l}\text { Experience and judgment } \\
\text { strongly favor one activity } \\
\text { over another }\end{array}$ \\
\hline 7 & Demonstrated importance & $\begin{array}{c}\text { An activity is strongly } \\
\text { favored, and its dominance is } \\
\text { demonstrated in practice }\end{array}$ \\
\hline 9 & Absolute importance & $\begin{array}{l}\text { The evidence favoring one } \\
\text { activity over another is of the } \\
\text { highest impossible order of } \\
\text { affirmation }\end{array}$ \\
\hline $2,4,6,8$ & $\begin{array}{l}\text { Intermediate values between } \\
\text { the two adjacent judgments }\end{array}$ & When compromise is needed \\
\hline Reciprocals of above nonzero & $\begin{array}{l}\text { If activity } i \text { has one of the } \\
\text { above nonzero numbers } \\
\text { assigned to it when compared } \\
\text { with activity } j \text {, then } j \text { has the } \\
\text { reciprocal value when } \\
\text { compared with } i\end{array}$ & \\
\hline
\end{tabular}

Synthesis: Calculating the priorities of the alternatives. The weights of the criteria and the priorities of each alternative on each criterion are used to calculate the final priorities and the overall ranking of the alternatives. In this step, a consistency test is performed for the entire hierarchy tree. The comparison matrices are consistent if the consistency ratio $C R=C I / R I$, is less than $10 \%$. The consistency ratio is calculated by the equation $C R=C I / R I$, where $C I$ is the consistency index of the matrix and RI is a "random consistency index" whose value depends on the dimension of the matrix. If the consistency ratio $C R$ is higher than $10 \%$, "the quality of the judgment data should be improved" [31].

Sensitivity Analysis: The sensitivity analysis is conducted in previous studies to examine the suitability of assigned weights by consultants. Some studies only applied the same weights for all criteria, while others benefited from the same weight for all AHP criteria and also removing some specific criteria to analyze the results [40,41].

\subsection{Implementation of the Proposed Model for Developing EV Charging Stations}

The objective of the proposed model is to select the optimal approach for developing and operating EV charging stations from the e-mobility investors/stakeholders' point of view in Greece, in other terms to define the appropriate business model among the existing alternatives [42]. The goal of the model represents the top level of the hierarchy tree (Level 1).

Regarding the technical aspects of the charging stations, according to the legal framework in Greece, charging stations equipped with IEC 61851-1 Mode 3 and Mode 4 outlets are permitted for public charging points. The Mode 4 DC charging stations due to the higher power level they deliver, and the quick charging time are suitable to be installed along motorways, while normal Mode $3 \mathrm{AC}$ charging stations are more likely to be installed within urban areas. This charging technology and location-specific distinction is the primary component for defining the alternative approaches:

- Installation of high-power Mode 4 DC charging stations on national road/motorways;

- Installation of normal power Mode 3 AC stations within urban areas. 
Furthermore, the publicly accessible charging stations in urban areas may be located on public spaces (e.g., public streets, open spaces, etc.) or private property (commercial building parking facilities, private indoor/outdoor car parking lots, etc.).

The infrastructure market model is applied at this stage. According to the Greek legal framework, the public charging infrastructure is developed (installation, ownership, operation) by any private organization. In addition, for public charging points located on land owned by the municipality, these can be developed by private organizations following public procurements that are being performed by municipalities. In this political context, and in conjunction with the above technical and location distinctions, the final alternatives for evaluation are developed:

- Alternative A: Installation and operation of high-power Mode 4 DC $50 \mathrm{~kW} \mathrm{CCS} \mathrm{+} \mathrm{DC}$ $50 \mathrm{~kW}$ CHAdeMO publicly accessible charging points that are installed in highways and the national road network. Development by a private organization.

- Alternative B: Installation and operation of normal Mode 3 AC $2 \times 22 \mathrm{~kW}$ Type 2 charging station, publicly accessible charging points that are installed at private spaces, within urban areas. Development by a private organization.

- Alternative C: Installation and operation of normal Mode 3 AC $2 \times 22 \mathrm{~kW}$ Type 2 charging stations, publicly accessible charging points that are installed at public spaces, within urban areas. Development and operation by a private organization after public procurements that are performed by the Municipalities.

For the sake of clarity, the power level and connector type of connectors of the charging stations are accurately described. High power charging stations are equipped with two charging outlets, Combo 2 (CCS) and CHAdeMO plugs for interoperability purposes. For normal power charging stations, the $2 \times 22 \mathrm{~kW}$ Type 2 plug is selected, as it is the main trend for public/private normal power charging points in Europe [43]. The alternative actions represent the fourth level (Level 4) of the hierarchy tree.

The literature review conducted in Section 2.1 'Charging infrastructure for EV' reveals a list of significant economic and technical factors to be considered in the decision-making process for the charging infrastructure market. However, in addition to these essential technoeconomic parameters, a wider consideration of factors should be made due to the public dimension of the EV charging infrastructure. In their research regarding the public project selection criteria based on a multicriteria decision analysis, Bellos et al. [44] highlight the importance of social and political criteria and use the following six clusters of criteria: Economic, political, social, sustainable development (environmental), and technical. With regards to applying a multi-criteria decision-making method for the optimal siting of charging stations from the sustainability perspective, Zhao \& Li. [45] also include social and environmental factors. In this research paper, the above-mentioned six clusters are applied, and the sub-criteria are identified in the literature.

A. Economic criteria: Cost is a significant factor for selecting a project.

1. Equipment cost: It significantly affects the value proposition of the charging infrastructure and differs between charging technologies $[9,23,25,46]$.

2. Power grid connection cost: It varies according to the power level of the charging station, and especially when the new power connection is required $[10,23]$.

3. Operating and maintenance cost: Operation expenses (electricity cost) and maintenance costs (planned and unplanned) [10,23].

B. Technical criteria: Technical characteristics of a charging station as well as the approval procedures required for the implementation of the infrastructure.

1. Charging station capacity: The power level of the charging station determines the maximum number of charging sessions per day. The charging sessions that the charging station can serve are essentially the "sales" units of the investment. A high power $50 \mathrm{~kW}$ charging station can serve up to 60 charging sessions per $24 \mathrm{~h} \mathrm{[10],} \mathrm{while} \mathrm{the} \mathrm{maximum} \mathrm{capacity} \mathrm{of} \mathrm{a} \mathrm{normal} \mathrm{power} 22 \mathrm{~kW}$ station is limited to 26 charging sessions. 
2. Power grid capacity: Power grid capacity is an important factor to be accounted for during planning the charging infrastructure [20] Major technical work may occur either due to strengthening the existing network or to the need of transformer installations.

3. Installation permits: Necessary authorizations and approval procedures are strong factors for selecting a project [44]. In addition to the licensing procedures for the charging station installation, construction approvals may be required depending on the space ownership and type.

4. Spatial coordination with urban development planning for parking reservation: The need for the spatial coordination of the charging infrastructure within urban areas is pointed out by [19]. The Greek legislation follows a similar direction and provides the development of spatial EV charging point plans by municipalities [47].

C. Social criteria: Acceptance of a project by the community is an important factor for the viability of the project [44]:

1. Estimated number of EVs: One of the main incentives for investing in charging infrastructure is the EV penetration level [48]. The official forecasts of EV penetration are a useful indicator.

2. Competition from home/private charging: Despite the need for public charging infrastructure, home/private charging appears to have high rates of preference by EV users. In their survey for the EV users in Norway, Figenbaum and Kolbenstvedt [21] find that the $94-95 \%$ of EV users choose the home charging or slow charging at the workplace, and the rates are equally high to $88 \%$ in a case in Austria [49].

D. Sustainable development/environmental criteria: The environmental benefits of a project and its contribution to sustainable development.

1. Improved air quality and noise reduction: The deployment of e-mobility contributes to greenhouse gas emissions reduction in the transportation sector through decarbonization. Internal combustion engine vehicles cause significant noise pollution and have an adverse effect on community health [50].

2. Sustainable development of areas of charging station installation: The study in economic and quantitative terms shows the benefits of e-mobility in the health sector [51], which exceed the cost of financial incentives for EV acquisition even in an adverse EV penetration scenario [52].

E. Political/policy criteria: Central and local government policy for the promotion of emobility affects decision-making in investment in the charging infrastructure market.

1. Incentive strategies and subsidies for an increasing EV fleet: The adoption of measures, either financial incentives for EV purchase [52] or non-financial traffic incentives for EVs [53], or tax exemptions and subsidies for charging infrastructure [48], all play a positive effect on the promotion of e-mobility, especially at the early stage of the market, when the economic viability of investments in charging infrastructure is uncertain.

2. Maturity of legal framework for the implementation of tenders: The legal framework has been recently granted. Especially in the case of developing public charging points through open tenders held by a municipality, the limited experience for the implementation may adversely affect the interest in the charging infrastructure market.

The second and third level of the hierarchy tree consists of these five criteria and the relative thirteen sub-criteria. The AHP tree of the research model is shown in Figure 1. 


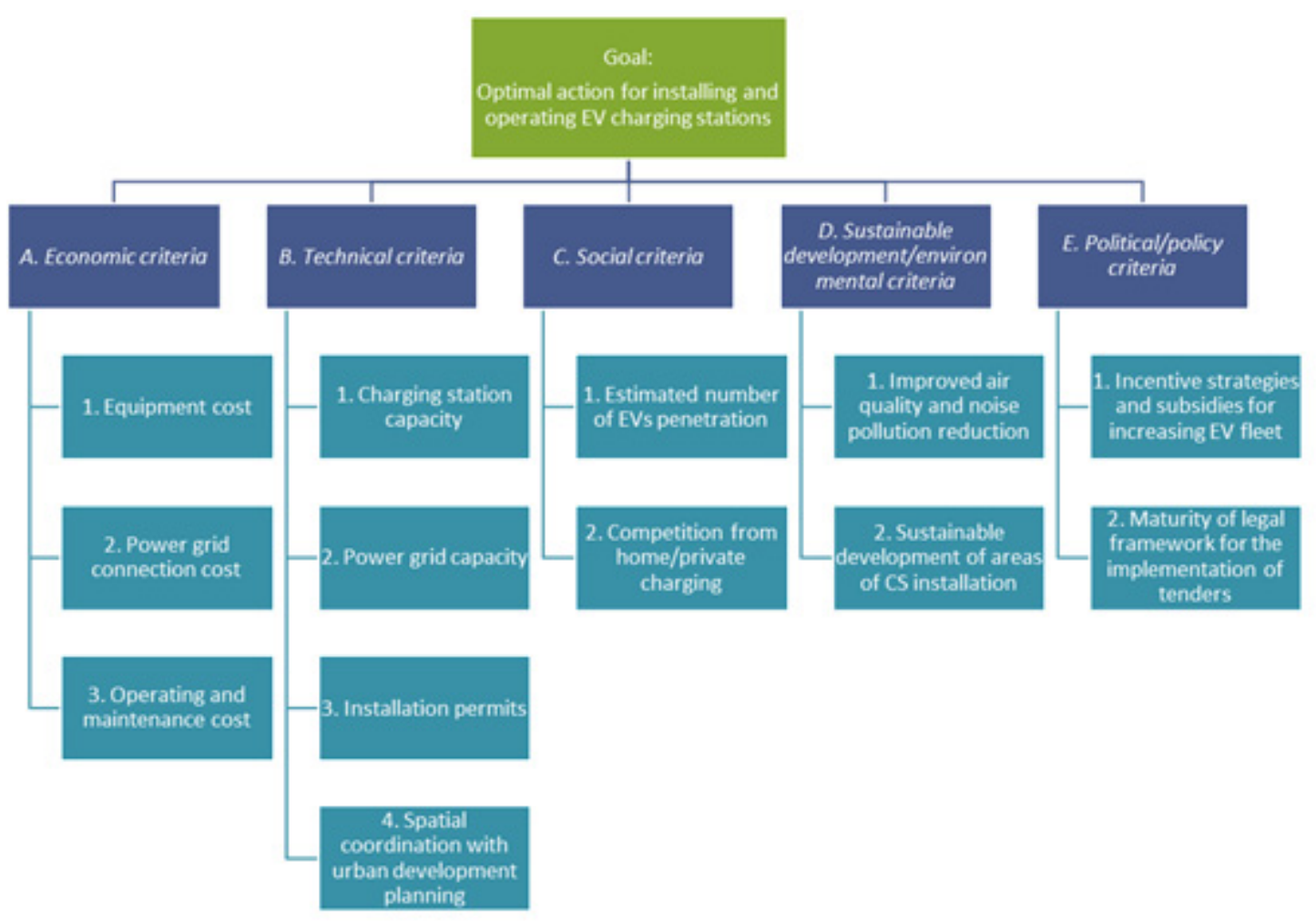

Figure 1. AHP tree for the research model.

The questionnaire used for the survey was developed based on the hierarchy model and its structure consists of the following sections:

- Section 1: Ten pairwise comparisons (Level 2) of the criteria for assessing their relevant importance with respect to the goal of the research model.

- Section 2: Twelve pairwise comparisons (Level 3) of the sub-criteria for assessing their relevant importance with respect to the parent criterion.

- Section 3: Forty-five pairwise comparisons (Level 4) of the alternatives for assessing their relevant performance with respect to each sub-criterion.

To the judgements collection, a first sample of twenty participants was made. The participants were chosen from the energy provider vendors in Greece, which have been eng0aged in the charging infrastructure market. Initially, the sample was contacted through phone calls to secure their participation in the survey. Four of the seven representatives agreed to participate. Given the specific subject of the survey and the limited range of companies operating in the Greek charging infrastructure market, the sample size was considered acceptable for this study. The final evaluators were technical or market managers of these companies, with knowledge of the charging infrastructure industry. The questionnaire was sent to participants via email, which explained the purpose of the study and the interviews were scheduled. The questionnaires were completed during phone interviews, to avoid invalid responses. The method of judgement collection for this research falls within the category of phone structured interview [54], where questions and content were strictly pre-defined, and they were the same for all participants. The data for each interview and a description of each participant's company are shown in Table 4.

The model was built and solved with the Expert Choice ${ }^{\circledR}$ software. First, the factors of the proposed model were entered, according to the hierarchy tree structure. Then, the participants' judgements were entered, which were combined in geometric means for each pairwise comparison. 
Table 4. Survey data.

\begin{tabular}{ccc}
\hline Company Description & Date of Interview & Duration (min) \\
\hline $\begin{array}{c}\text { Company for energy services and technical } \\
\text { facility management/maintenance, e-mobility } \\
\text { service provider. }\end{array}$ & 7 March 2020 & 45 \\
\hline $\begin{array}{c}\text { Production and supply of electrical equipment } \\
\text { for power distribution network, supply and } \\
\text { installation of EV charging equipment, } \\
\text { management services. }\end{array}$ & 7 March 2020 & 75 \\
\hline $\begin{array}{c}\text { Provision of maintenance and support services } \\
\text { for power plants, supply of EV charging } \\
\text { equipment, installation, and } \\
\text { management services. }\end{array}$ & 7 April 2020 & 90 \\
\hline $\begin{array}{c}\text { Oil trading company that has installed EV } \\
\text { charging stations on its service stations. }\end{array}$ & 7 March 2020 & 49 \\
\hline
\end{tabular}

\subsection{Findings and Discussion}

The results were extracted after the priorities calculation and synthesis performance. Regarding the objective of the proposed model, the highest value of performance of 0.373 corresponds to Alternative $B$, followed by Alternative $C$ with a performance value of 0.327 and Alternative A with a performance value of 0.301 . The final ranking of the alternatives and their performance with respect to each criterion are shown in Figure 2. In this diagram, the weight of each criterion $(L)$ and the overall consistency ratio of the model $(C R=0.07)$ are depicted. As the consistency ratio is less than 0.1 , the judgmental data are consistent and perfectly acceptable.

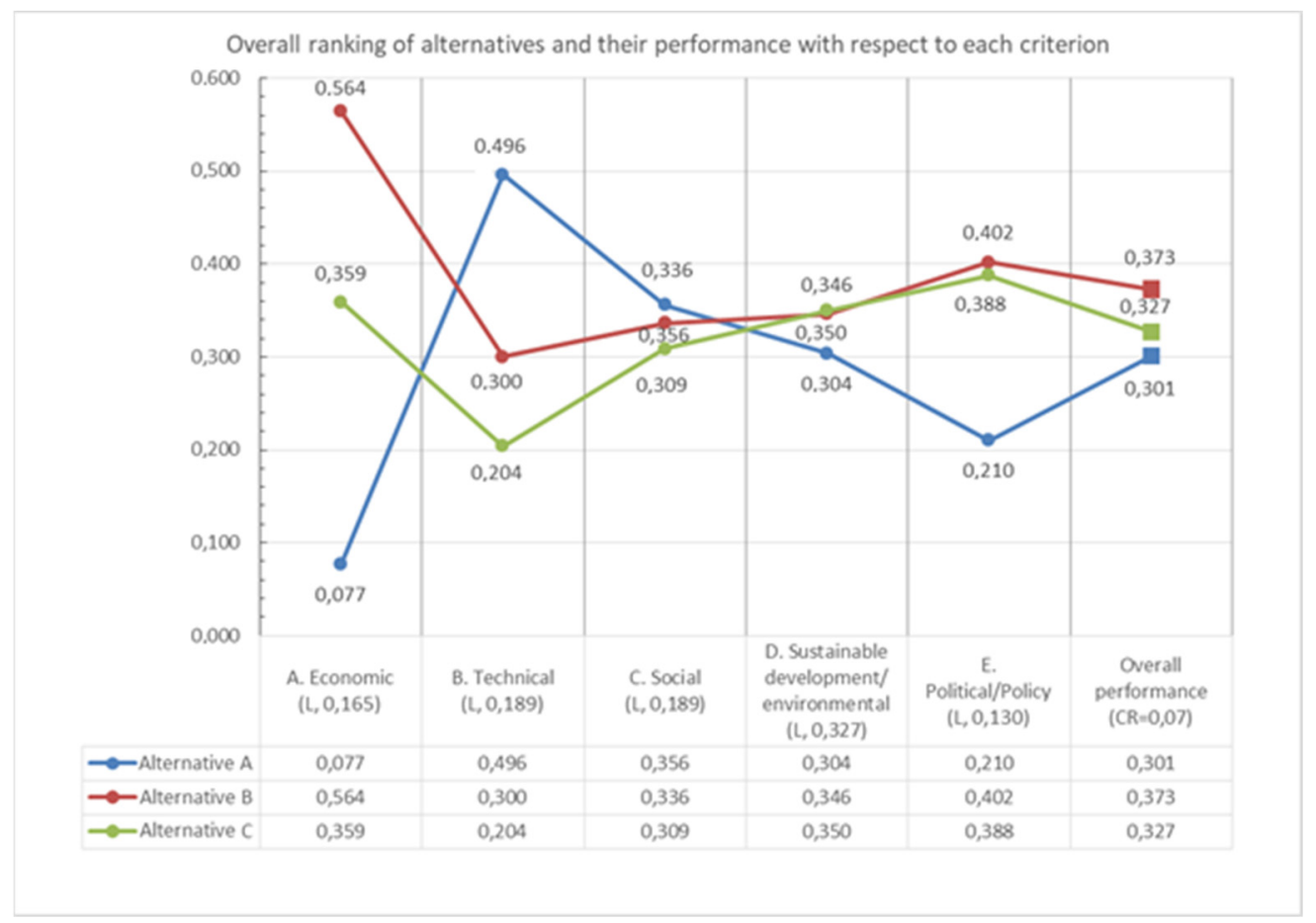

Figure 2. Overall ranking of alternative actions and their performance by criterion.

Alternative B received the highest score 0.564 in the economic criteria. According to the participants' judgements, although Alternatives B and C refer to the same technical characteristics in terms of power level and connector type, they differ significantly in the overall investment costs. Alternative $C$ usually requires a new power connection-due 
to the public space location of the station, unlike Alternative B. In addition, the charging station that must be installed in a public place requires anti-vandal protection, which increases equipment costs, as well as high maintenance and operation costs. Regarding the political/policy criteria, Alternative B obtains the second highest score 0.402 of performance as it is positively affected by the incentives policy, while it does not require long installation procedures.

Alternative $C$ is ranked second, it has the highest score of 0.350 in the sustainable development/environmental criteria, and the most important cluster according to the participants. In addition, Alternative $C$ is highly evaluated in the political criteria as it is chosen as clearly preferable in terms of incentive strategies and subsidies $(0.453)$ but lags significantly (0.123) behind the other two alternatives in terms of the maturity of the regulation framework for its implementation.

Finally, Alternative A-installation and operation of a high-power charging station on highways and national roads-obtains the highest score (0.496) in the technical criteria, as it is selected as clearly preferable (0.764) regarding the sub-criterion of charging station capacity that signifies a high level of service. As it was expected, its lowest performance value (0.007) refers to the economic criteria.

The weights of criteria and sub-criteria with respect to the parent criterion are presented in Figure 3. Participants gave the highest importance score (0.327) at the sustainable development/environmental criteria. Next and equally important (0.189) are the technical and social criteria, followed by the economic criteria (0.165). The political/policy criteria were not considered important to the objective achievement and were evaluated as less important (0.130). Regarding the importance of the sub-criteria, the most important ones with respect to the parent criterion are the equipment cost (economic); charging station capacity (technical); estimated number of EVs penetration (social); improvement of air quality (sustainable development/environmental); and incentives strategies and subsidies (political/policy). The consistency ratios of the sub-criteria comparison matrixes are also shown in Figure 3, next to the parent criterion. All the values are much lower than $10 \%$.
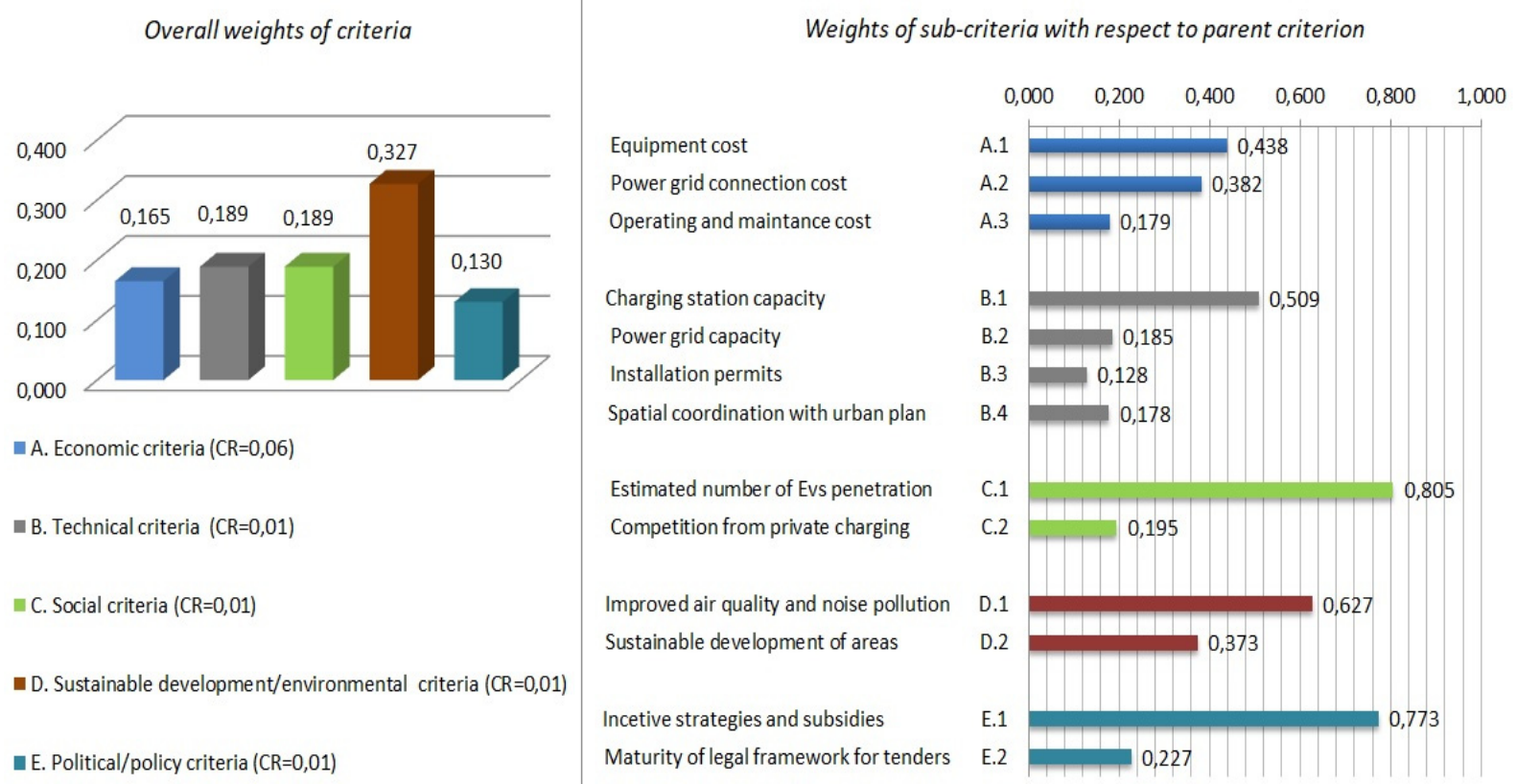

Figure 3. Weights of criteria and weights of sub-criteria with respect to the parent criterion.

The consistency check is a tool for the quality control of judgmental data. In addition, the AHP method enables the examination of the results by performing a sensitivity analysis. The purpose of the sensitivity analysis is to determine how changes in the factors importance affect the result. The sensitivity analysis for the proposed model is performed in the 
Expert Choice ${ }^{\circledR}$ software and changes of $50 \%$ in the priorities of all criteria clusters did not affect the optimal option. The importance degree of economic criteria should be reduced to 0.021 , a percentage change of $87.3 \%$, to change the overall ranking with Alternative A as the optimal action. Similar extreme changes should be performed for the technical, social, and sustainable development/environmental criteria to affect the final ranking. For example, the priority of the technical criteria should be increased from 0.189 to 0.417 (percentage change of $120.6 \%$ ) to result in Alternative A as the optimal action. Regarding the political/policy criteria, no range of change affects the overall classification.

The performed sensitivity analysis of the model validated the results. Alternative B remains the optimal option despite the high percentage change of $50 \%$ in the criteria priorities and the close ranking of the alternatives.

\section{Conclusions}

This study was two-fold and attempted first, to define the options for EV charging network's deployment and second, to present the decision-making process for such network's deployment and operation. More specifically, this article addressed the challenges for EV market growth and grounded two research questions: The first one (RQ1) aimed to identify the technical characteristics of EV charging stations for publicly accessible and the alternative business models for their deployment. Literature review findings provided answer RQ1 (Tables 1 and 2) for EV charging options and three business model alternatives (A, B, and C) were discovered.

Regarding RQ2 and the identification of the most suitable business model for EV charging network's deployment and operation in Greece, the AHP methodology was followed with the participation of four representatives from the corresponding energy provision market. The methodology accounted for all potential factors (economic, technical, social, environmental, and political), the location's selection (motorways/urban areas, public/private space), and the EV charging infrastructure market model. The followed model can also support the development of a business plan in the EV charging infrastructure market.

Based on the results of the AHP model, Alternative B of the installation and operation of normal power charging stations, publicly accessible in private space within urban areas, by a private body, was selected as the optimal option. The advantage of Alternative $B$ is based on the low-risk investment, and its dominance in the political/policy criteria, while at the same time, its significant contribution to sustainability. Alternative $\mathrm{C}$ follows, since the participants considered it essential for the sustainable development, the degree of which depends high on the energy production sources. The weakness of Alternative A is the high infrastructure cost, but it is ranked high in technical factors due to the equipment features.

Regarding the criteria relative importance, the sustainable development/environmental factors received the highest score, followed by the technical and social factors. According to the participants' judgments, it can be concluded that investments in the charging infrastructure market in Greece, are not guided by economic perspectives, but mainly by sustainable and environmental benefits.

The sensitivity analysis was performed on the AHP findings, which showed that changing the priorities of the criteria did not affect the optimal choice (Alternative B). The proposed decision-making framework appears to be reliable for determining an optimal approach for developing and operating EV charging stations in the Greek market, which is a representative European case that enters the EV era.

Nevertheless, certain limitations should be considered. During the research process, the legal framework for the promotion and organization of the e-mobility market was in progress, as it was finalized and adopted in July 2020. No pilot had been carried out at the national or local level. Furthermore, the early stage of e-mobility market in Greece and the small-scale development of charging infrastructure posed an additional limitation. Still, although Greece is a representative European case, limitations come from the political 
and economic conditions of the country, which affect market decisions and new entrants. Moreover, due to the limited amount of energy providers that operate in the Greek charging infrastructure market (seven), there was a small number of participants in the survey.

Some future thoughts concern model testing again after the application of the updated legal framework for EV deployment and especially with the contribution of an extended number of participants. Especially in the case of Alternative C, uncertainties such as duration of the concession, award criteria, and contactors' obligations would be addressed. Moreover, the availability of financial data on revenues of each alternative action would allow financial indicators such as the internal rate of investment ROI to be included in the economic criteria of the research model. Finally, from a methodological approach, it would be an interesting economic case study of Alternative $\mathrm{C}$.

Moreover, literature review updates should be added in future studies, which will return new findings in the domain of EV charging stations' deployment methodologies and potential alternative funding schemas. Moreover, future thoughts will expand the interviews to an extended sample of experts, who will be familiar in the topic and engaged in the deployment of EV charging stations in Greece and probably in other countries, as well. Similarly, findings could be tested in other countries to validate the outcomes under different political and economic conditions.

Author Contributions: Conceptualization, L.A. and P.K.; methodology, P.K.; software, P.K.; validation, L.A. and P.K.; formal analysis, L.A. and P.K. investigation, P.K.; resources, P.K.; data curation, P.K.; writing—original draft preparation, P.K.; writing—review and editing, L.A.; visualization, P.K.; supervision, L.A.; project administration, L.A.; funding acquisition, L.A. Both authors have read and agreed to the published version of the manuscript.

Funding: This research received no external funding.

Institutional Review Board Statement: Not applicable.

Informed Consent Statement: Not applicable.

Data Availability Statement: Not applicable.

Conflicts of Interest: The authors declare no conflict of interest.

\section{References}

1. European Commission. A European Green Deal. Available online: https://ec.europa.eu/info/strategy/priorities-2019-2024/ european-green-deal_en (accessed on 18 September 2020).

2. European Commission. Sustainable and Smart Mobility Strategy_Putting European Transport on Track for the Future. Available online: https: / / ec.europa.eu/transport/sites/default/files/legislation/com20200789.pdf (accessed on 10 July 2021).

3. European Alternative Fuels Observatory. Report on Greece, Normal and Fast Public Charging Points. Available online: https://www.eafo.eu/countries/greece/1735/summary (accessed on 10 July 2021).

4. European Alternative Fuels Observatory. Report on Greece, Normal and Fast Public Charging Points. Available online: https: / / www.eafo.eu/countries/greece/1735/infrastructure/electricity (accessed on 18 September 2020).

5. International Energy Agency. Global EV Outlook 2019: Scaling-up the Transition to Electric Mobility. Available online: https: //www.oecd-ilibrary.org/energy/global-ev-outlook-2019_35fb60bd-en (accessed on 18 September 2020).

6. Coffman, M.; Bernstein, P.; Wee, S. Electric vehicles revisited: A review of factors that affect adoption. Transp. Rev. 2017, 37, 79-93. [CrossRef]

7. Hidrue, M.K.; Parsons, G.R.; Kempton, W.; Gardner, M.P. Willingness to pay for EV and their attributes. Resour. Energy Econ. 2011, 33, 686-705. [CrossRef]

8. Kley, F.; Lerch, C.; Dallinger, D. New business models for electric cars-A holistic approach. Energy Policy 2011, 39, 3392-3403. [CrossRef]

9. Madina, C.; Zamora, I.; Zabala, E. Methodology for assessing EV charging infrastructure business models. Energy Policy 2016, 89, 284-293. [CrossRef]

10. Schroeder, A.; Traber, T. The economics of fast charging infrastructure for EV. Energy Policy 2012, 43, 136-144. [CrossRef]

11. Nieuwenhuis, P.; Wells, P. New Business Models for Alternative Fuel and Alternative Powertrain Vehicles; An Infrastructure Perspective. New Business Models for Alternative Fuel and Powertrain Vehicles. Available online: https://www.oecd.org/futures/ New\%20Business\%20Models\%20for\%20Alternative\%20Fuel\%20and\%20Alternative\%20Powertrain\%20vehicles.pdf (accessed on 18 September 2020). 
12. Ministry of Environment and Energy. National Plan for Energy and Climate; Ministry of Environment and Energy: Athens, Greece, 2019. (In Greek)

13. International Electrotechnical Commission (IEC). EV Conductive Charging System-Part 1: General Requirements 2017. Available online: https:/ / webstore.iec.ch/publication/33644 (accessed on 10 July 2021).

14. Falvo, M.C.; Sbordone, D.; Bayram, I.S.; Devetsikiotis, M. EV charging stations and modes: International standards. In Proceedings of the 2014 International Symposium on Power Electronics, Electrical Drives, Automation and Motion, Ischia, Italy, 18-20 June 2014; pp. 1134-1139. [CrossRef]

15. Government Gazette (2040/B/2019). Terms, Conditions and Technical Specifications for the Installation of EV Recharging Devices, at Existing or in the Process of Being Licensed Car Parks at the Port Zone and/or Tourist Ports (Marinas), at Existing or in the Process of Being Licensed Indoor and Outdoor Car Parks, at Existing or in the Process of Being Licensed Car, Motorcycle and Motorbike Maintenance and Repair Shops, at Existing or in the Process of Being Licensed Public or Private Vehicle Roadworthiness Testing Centers, at Publicly Accessible Recharging Points Along the Length of Urban, Intra-Urban and National Road Network, at Parking Facilities in Public and Private Buildings, and Also at Terminal Stations or Transit Stations for Passengers of Public Means of Transport. Joint Ministerial Decision No 42863/438; National Printing Office: Athens, Greece, 2020. (In Greek)

16. Das, H.; Rahman, M.; Li, S.; Tan, C. Electric vehicles standards, charging infrastructure, and impact on grid integration: A technological review. Renew. Sustain. Energy Rev. 2019, 120, 109618. [CrossRef]

17. Longo, M.; Zaninelli, D.; Viola, F.; Romano, P.; Miceli, R.; Caruso, M.; Pellitteri, F. Recharge stations: A review. In Proceedings of the 11th International Conference on Ecological Vehicles and Renewable Energies (EVER), Monte Carlo, Monaco, 6-8 April 2016. pp. 1-8. Available online: http:/ / ieeexplore.ieee.org/document/7476390/ (accessed on 18 September 2020).

18. Martínez-Lao, J.; Montoya, F.G.; Montoya, M.G.; Manzano-Agugliaro, F. EV in spain: An overview of charging systems. Renew. Sustain. Energy Rev. 2017, 77, 970-983. [CrossRef]

19. Bakker, S.; Maat, K.; van Wee, B. Stakeholders interests, expectations, and strategies regarding the development and implementation of EV: The case of the Netherlands. Transp. Res. Part A Policy Pract. 2014, 66, 52-64. [CrossRef]

20. Burnham, A.; Dufek, E.J.; Stephens, T.; Francfort, J.; Michelbacher, C.; Carlson, R.B.; Zhang, J.; Vijayagopal, R.; Dias, F.; Mohanpurkar, M.; et al. Enabling fast charging_-Infrastructure and economic considerations. J. Power Sources 2017, 367, 237-249. [CrossRef]

21. Figenbaum, E.; Kolbenstvedt, M. Learning from Norwegian Battery Electric and Plug-In Hybrid Vehicle Users; Institute of Transport Economics, Norwegian Centre for Transport Research: Oslo, Norway, 2016; Available online: https: / / www.toi.no/publications/learning-from-norwegian-battery-electric-and-plug-in-hybrid-vehicle-users-results-from-asurvey-of-vehicle-owners-article33869-29.html (accessed on 10 July 2021).

22. Serradilla, J.; Wardle, J.; Blythe, P.; Gibbon, J. An evidence-based approach for investment in rapid-charging infrastructure. Energy Policy 2017, 106, 514-524. [CrossRef]

23. Levinson, R.S.; West, T.H. Impact of public EV charging infrastructure. Transp. Res. Part D Transp. Environ. 2018, 64, 158-177. [CrossRef]

24. Markkula, J.; Rautiainen, A.; Jarventausta, P. The business case of EV quick charging. No more chicken or egg problem. In Proceedings of the 2013 World EV Symposium and Exhibition (EVS27), Barcelona, Spain, 17-20 November 2013 ; pp. 1-7. Available online: https:/ / ieeexplore.ieee.org/document/ 6915043 (accessed on 18 September 2020).

25. German National Platform for Electric Mobility. Charging Infrastructure for EV in Germany Progress Report and Recommendations 2015. Available online: http:/ / nationale-plattform-elektromobilitaet.de/fileadmin/user_upload/Redaktion/AG3 _Statusbericht_LIS_2015_engl_klein_bf.pdf (accessed on 18 September 2020).

26. Marra, F.; Traholt, C.; Larsen, E. Planning future EV central charging stations connected to low-voltage distribution networks. In Proceedings of the 3rd IEEE International Symposium on Power Electronics for Distributed Generation Systems (PEDG), Aalborg, Denmark, 25-28 June 2012; pp. 636-641. Available online: http:/ /ieeexplore.ieee.org/document/6254069/ (accessed on 18 September 2020).

27. Eurelectric. Deploying Publicly Accessible Charging Infrastructure for EV: How to Organise the Market? Eurelectric: Brussels, Belgium, 2013.

28. Papathanasiou, S. Institutional Framework of the EV Recharging Services Market in Greece. 2019. Available online: https: / / energypress.gr/sites/default/files/media/003_-_papathanasiou_-_final.pdf. (accessed on 18 September 2020). (In Greek).

29. van Deventer, P.; van der Steen, M.; van Schelven, R.; Rubin, B.; Kotter, R. Large-Scale Deployment of Public Charging Infrastructure: Identifying Possible Next Steps Forward. In E-Mobility in Europe. Green Energy and Technology; Filho, W.L., Kotter, R., Eds.; Springer International Publishing: Cham, Switzerland, 2015; pp. 107-124. [CrossRef]

30. Hall, D.; Lutsey, N. Emerging Best Practices for EV Charging Infrastructure; The International Council on Clean Transportation (ICCT): Washington, DC, USA, 2017; p. 54.

31. Wind, Y.; Saaty, T.L. Marketing Applications of the Analytic Hierarchy Process. Manag. Sci. 1980, 26, 641-658. [CrossRef]

32. Vaidya, O.S.; Kumar, S. Analytic hierarchy process: An overview of applications. Eur. J. Oper. Res. 2006, 169, 1-29. [CrossRef]

33. Rehman, A.; Shekhovtsov, A.; Rehman, N.; Faizi, S.; Sałabun, W. On the Analytic Hierarchy Process Structure in Group Decision-Making Using Incomplete Fuzzy Information with Applications. Symmetry 2021, 13, 609. [CrossRef]

34. Grošelj, P. Symmetric projection group approach for promoting homogeneity in the analytic hierarchy process. Comput. Oper. Res. 2021, 133, 105343. [CrossRef] 
35. Sałabun, W.; Shekhovtsov, A.; Pamučar, D.; Wątróbski, J.; Kizielewicz, B.; Więckowski, J.; Bozanić, D.; Urbaniak, K.; Nyczaj, B. A Fuzzy Inference System for Players Evaluation in Multi-Player Sports: The Football Study Case. Symmetry 2020, 12, 2029. [CrossRef]

36. Sałabun, W.; Wątróbski, J.; Shekhovtsov, A. Are MCDA Methods Benchmarkable? A Comparative Study of TOPSIS, VIKOR, COPRAS, and PROMETHEE II Methods. Symmetry 2020, 12, 1549. [CrossRef]

37. Shekhovtsov, A.; Sałabun, W. A comparative case study of the VIKOR and TOPSIS rankings similarity. Procedia Comput. Sci. 2020, 176, 3730-3740. [CrossRef]

38. Becker, J.; Becker, A.; Sałabun, W. Construction and Use of the ANP Decision Model Taking into Account the Experts' Competence. Procedia Comput. Sci. 2017, 112, 2269-2279. [CrossRef]

39. Tsinidou, M.; Gerogiannis, V.; Fitsilis, P. Evaluation of the factors that determine quality in higher education: An empirical study. Qual. Assur. Educ. 2010, 18, 227-244. [CrossRef]

40. Saaty, R. The analytic hierarchy process-What it is and how it is used. Math. Model. 1987, 9, 161-176. [CrossRef]

41. Kizielewicz, B.; Watróbski, J.; Sałabun, W. Identification of Relevant Criteria Set in the MCDA Process-Wind Farm Location Case Study. Energies 2020, 13, 6548. [CrossRef]

42. Anthopoulos, L.; Fitsilis, P.; Ziozias, C. What is the source of smart city value? A business model analysis. In Smart Cities and Smart Spaces: Concepts, Methodologies, Tools, and Applications; IGI Global: Hershey, PA, USA, 2019; pp. 56-77.

43. LeGoy, P.R.; Buckley, G.J.M. Low voltage grid connections for EV infrastructure in Europe. In Proceedings of the 2012 IEEE Power and Energy Society General Meeting, San Diego, CA, USA, 22-26 July 2012; pp. 1-8. Available online: http:/ /ieeexplore.ieee.org/ document/6344884/ (accessed on 18 September 2020).

44. Bellos, E.; Voulgaridou, D.; Kirytopoulos, K.; Panopoulos, D. An MCDA approach for project selection in public sector. In Proceedings of the 5th Scientific Conference on Project Management, Crete, Greece, 29-31 May 2010; Available online: https: //www.academia.edu/1097802/An_MCDA_Approach_for_Project_Selection_in_Public_Sector (accessed on 18 September 2020).

45. Zhao, H.; Li, N. Optimal siting of charging stations for EV based on fuzzy delphi and hybrid multi-criteria decision making approaches from an extended sustainability perspective. Energies 2016, 9, 270. [CrossRef]

46. Soykan, E.U.; Bagriyanik, M.; Soykan, G. Disrupting the power grid via EV charging: The impact of the SMS Phishing attacks. Sustain. Energy Grids Netw. 2021, 26, 100477. [CrossRef]

47. Government Gazette (147/A/2020). On the Promotion of e-Mobility, Law 4710/2020; National Printing Office: Athens, Greece, 2020. (In Greek)

48. Fang, Y.; Wei, W.; Mei, S.; Chen, L.; Zhang, X.; Huang, S. Promoting EV charging infrastructure considering policy incentives and user preferences: An evolutionary game model in a small-world network. J. Clean. Prod. 2020, 258, 120753. [CrossRef]

49. Baresch, M.; Moser, S. Allocation of e-car charging: Assessing the utilization of charging infrastructures by location. Transp. Res. Part A Policy Pract. 2019, 124, 388-395. [CrossRef]

50. OECD. The Cost of Air Pollution: Health Impacts of Road Transport. Available online: https://www.oecd-ilibrary.org/ environment/the-cost-of-air-pollution_9789264210448-en (accessed on 18 September 2020).

51. Gai, Y.; Minet, L.; Posen, I.D.; Smargiassi, A.; Tétreault, L.-F.; Hatzopoulou, M. Health and climate benefits of EV deployment in the greater toronto and hamilton area. Environ. Pollut. 2020, 265, 114983. [CrossRef]

52. Bjerkan, K.Y.; Nørbech, T.E.; Nordtømme, M.E. Incentives for promoting battery EV (bev) adoption in norway. Transp. Res. Part D Transp. Environ. 2016, 43, 169-180. [CrossRef]

53. Lieven, T.; Rietmann, N. Do policy measures in fact promote electric mobility? A study across 20 countries. Int. J. Transp. Dev. Integr. 2017, 2, 39-48. [CrossRef]

54. Saunders, M.N.K.; Lewis, P.; Thornhill, A. Research Methods for Business Students, 5th ed.; Prentice Hall: New York, NY, USA, 2009. 